Abstract G83 Table 2 Sensitivity and specificitiy rates

\begin{tabular}{ll}
\hline Sensitivity & $\mathbf{9 8 . 4 \%}$ \\
\hline Specificity & $98.9 \%$ \\
Positive PV & $97.2 \%$ \\
Negative PV & $99.4 \%$ \\
\hline
\end{tabular}

Conclusion Neonatal echocardiography by neonatologists have high concordance rates and have a high sensitivity and specificity in detecting congenital heart diseases. With appropriate Paediatric Cardiology support Neonatal Echocardiography by neonatologists can be a safe and reliable tool.

\section{G84 A PARENTS VIEW OF CARDIAC SCREENING FOR DOWN SYNDROME}

doi:10.1136/archdischild-2013-304107.096

E Pascall, R Tulloh. Medical School, University of Bristol, Bristol, UK

Background Cardiac disorders are common in children with Down syndrome and the Down Syndrome Medical Interest Group (DSMIG) guidelines were updated in 2007. This project aims to review if parents thought these standards were being met.

Methods A survey reflecting the guidelines was posted by the Down Syndrome Heart Group on their webpage and on facebook. Parent responders shared the page in order to more replies. The questionnaire was intended to identify when the diagnosis of Down Syndrome was made, and the time it took for a cardiologist referral and echocardiogram.

Results 98 responses were collected and analysed. 85 responders lived in England (86.7\%). 23.65\% were diagnosed with Down syndrome prenatally, $70.25 \%$ were diagnosed within one week of birth and $6.1 \%$ more than one week after birth. $94.45 \%$ underwent foetal echocardiography of which $54.1 \%$ had the diagnosis confirmed after birth and $94.5 \%$ were seen by a paediatric cardiologist within 2 weeks after birth. Of those who did not undergo foetal echocardiography, $71.4 \%$ were seen within 6 weeks of birth, in whom $42.9 \%$ were found to have congenital heart disease. $73.4 \%$ of those diagnosed with Down syndrome within one week of age had an ECG at this time. Only 84\% of those with abnormal ECG were referred and seen by a paediatric cardiologist before 2 weeks of age. $14.2 \%$ were not seen by a cardiologist or underwent ECG within 6 weeks.

Conclusions The results of this parent led questionnaire show the majority of babies with Down syndrome are diagnosed within one week of birth. Most of the 2007 guidelines set by the DSMIG are being broadly met, however more emphasis should be made on meeting the deadlines for paediatric cardiology review and echocardiogram. This applies to whether diagnosis is made prenatally, within one week of birth or more than one week after birth. In addition only $73 \%$ of those that are diagnosed within a week undergo an immediate ECG. More importance needs to be based on adhering to the guidelines and reducing parental uncertainty about congenital heart disease in Down syndrome.

\section{British Paediatric Allergy, Immunology and Infection Group}

\section{G85 ADRENALINE USE IN ANAPHYLAXIS IN PAEDIATRIC WARDS IN UK}

doi:10.1136/archdischild-2013-304107.097

${ }^{1} \mathrm{M}$ Sundaram, ${ }^{2} \mathrm{~S}$ McGowan-Smyth, ${ }^{1 B}$ Tharayil, ${ }^{1,2}{ }^{2} \mathrm{M}$ Samuels. ${ }^{1}$ Academic Department of Paediatrics, University Hospital of North Staffordshire, Stoke on Trent, UK; ${ }^{2}$ Keele University School of Medicine, Newcastle under Lyme, UK
Background Resuscitation Council Guidelines (RC-UK, 2008) for treating anaphylaxis advocate intramuscular adrenaline in doses of 150, 300 or 500 micrograms, according to age bands [1]. However, ALS guidelines recommend weight-based calculations of 10 micrograms $/ \mathrm{kg} \mathrm{IM}$, leading to administration of a range of volumes [2].

Aims A survey was conducted to evaluate the availability of fixed dose Epipens versus adrenaline vials in paediatric wards and radiology departments in England.

Methods The questionnaire was sent to 105 paediatric pharmacists at the various paediatric units in UK.

Results $60 \%$ responding hospitals had adrenaline available, half of them in vials and $85 \%$ with prefilled variable-dose syringes. In $53 \%$ units, wards stocked adrenaline 1:10,000 and 64\% also had 1:1000. $19 \%$ hospitals stocked Epipens on crash trolleys and it was available in $48 \%$ wards. Adrenaline was given according to a weight-based dose in $57 \%$ wards. For contrast studies, adrenaline was available in $68 \%$ departments, $9.5 \%$ of which stocked Epipen.

Conclusion Most units still use weight-based doses of adrenaline from vials or pre-filled syringes, with Epipens being available in less than half of units. Adrenaline must always be available on wards and in radiology departments, as most arrests from anaphylaxis occur within 10 minutes. To ensure compliance with RC-UK guidelines, either all wards should stock Epipens or the guidelines should reflect practise and recommend weight-based calculated doses.

\section{REFERENCES}

1. Working Group of the Resuscitation Council (UK). Emergency treatment of anaphylactic reactions: Guidelines for healthcare providers: Resuscitation Council, 2008. Available at: http://www.resus.org.uk/pages/reaction.pdf (accessed 12 December 2012).

2. Samuels M, Wieteska S. Advanced Paediatric Life Support, 5th edition, WileyBlackwell Publishing, Oxford, 2011.

\section{G86 ANAPEN, EPIPEN AND JEXT AUTO-INJECTORS; ASSESSMENT OF SUCCESSFUL USE AFTER CURRENT TRAINING PACKAGE}

doi:10.1136/archdischild-2013-304107.098

${ }^{1}$ HM Luckhurst, ${ }^{2 D}$ Tuthill, ${ }^{2} \mathrm{~J}$ Brown, ${ }^{2 E}$ Spear, ${ }^{2} \mathrm{~J}$ Pitcher. ' $S$ School of Medicine, Cardiff University, Cardiff, UK; ${ }^{2}$ General Paediatrics, Cardiff and Vale UHB, Cardiff, UK

Background Anaphylaxis is a severe life threatening allergic reaction. Prompt administration of epinephrine(adrenaline) is the first line treatment. There are currently three epinephrine auto-injector devices available in the UK; original Anapen, new EpiPen and Jext, each of which differ in their advised method of use. International standards recommend training for all patients prescribed epinephrine auto-injectors, we meet these. If families can more successfully use a particular trainer device, this may have important clinical effects.

Aims To assess the effectiveness of the training by evaluating "epinephrine naive" families' ability to successfully use an auto-injector trainer device

Methods Adults and children over 12, with no experience of autoinjector use were invited to participate in this service evaluation. They were randomly allocated to be trained in the use of one of the available auto-injectors. Their performance was assessed using a ten point marking sheet based on the correct method of administration of epinephrine for the individual device. Six marks were for procedures identical to all three devices (e.g. massage the site of injection) and four were device specific to reflect the differences in administration technique. Success rates were analysed by Chi-square with $\mathrm{p}<0.05$ being deemed significant (http://graphpad.com/quickcalcs/ contingency 2).

Results There were 120 participants. 


\section{Abstract G86 Table 1}

\begin{tabular}{|c|c|c|c|c|c|c|}
\hline & $\begin{array}{l}\text { Ana- } \\
\text { pen }\end{array}$ & EpiPen & Jext & Chi & Chi & $\begin{array}{l}\text { All } \\
\text { partici- } \\
\text { pants } \\
(n=120)\end{array}$ \\
\hline $\begin{array}{l}\text { Scoring } 6 / 6 \text { for } \\
\text { identical procedures }\end{array}$ & $\begin{array}{l}16 \\
(40 \%)\end{array}$ & $\begin{array}{l}13 \\
(33 \%)\end{array}$ & $\begin{array}{l}16 \\
(40 \%)\end{array}$ & ns & ns & $\begin{array}{l}45 \\
(38 \%)\end{array}$ \\
\hline $\begin{array}{l}\text { Scoring } 4 / 4 \text { for device } \\
\text { specific procedures }\end{array}$ & $\begin{array}{l}36 \\
(90 \%)\end{array}$ & $\begin{array}{l}18 \\
(45 \%)\end{array}$ & $\begin{array}{l}22 \\
(55 \%)\end{array}$ & ns & 0.0001 & $\begin{array}{l}76 \\
(63 \%)\end{array}$ \\
\hline $\begin{array}{l}\text { Performing all } \\
\text { procedures correctly } \\
10 / 10\end{array}$ & $\begin{array}{l}16 \\
(40 \%)\end{array}$ & $\begin{array}{l}8 \\
(20 \%)\end{array}$ & $\begin{array}{l}10 \\
(25 \%)\end{array}$ & ns & ns & $\begin{array}{l}34 \\
(28 \%)\end{array}$ \\
\hline $\begin{array}{l}\text { Successfully firing } \\
\text { auto-injector trainer } \\
\text { pens }\end{array}$ & $\begin{array}{l}39 \\
(98 \%)\end{array}$ & $\begin{array}{l}28 \\
(70 \%)\end{array}$ & $\begin{array}{l}39 \\
(98 \%)\end{array}$ & 0.0024 & 0.0024 & $\begin{array}{l}106 \\
(88 \%)\end{array}$ \\
\hline
\end{tabular}

Conclusions Only $28 \%$ of participants were able to perform the individual device's 10 steps correctly. Overall the trainer devices fired in $88 \%$, with a failure rate of 2 to $30 \%$; a clinically and statistically significant result. The Epipen's swing and hit delivery method may affect its successful delivery compared to the Jext and Anapen's methods.

\section{G87 HOW MUCH DO JUNIOR DOCTORS KNOW ABOUT ANAPHYLAXIS?}

doi:10.1136/archdischild-2013-304107.099

N Dowling, J Richardson, G Harlow, N Makwana. Department of Paediatrics, Sandwell Hospital, Sandwell and West Birmingham NHS Trust, West Bromwich, UK

Anaphylaxis is a severe, life-threatening hypersensitivity reaction. NICE issued guidance in December 2011 regarding management of suspected anaphylaxis, the authors of which attribute suboptimal management to inadequate understanding by health care professionals.

Aim We aim to evaluate how suspected anaphylaxis was managed in a large NHS trust and to assess knowledge of trainees and final year medical students.

Method A retrospective case note analysis of patients under 17 years old coded with anaphylaxis between January 2007 and September 2012 comparing management to NICE guidance, was performed. This was supplemented by a survey (based on Advanced
Paediatric Life Support guidelines) of junior doctors and medical students. Participants assigned twenty clinical features to 'allergy', 'suspected anaphylaxis' or' neither' and selected suitable management options.

Results Table 1 illustrates initial management of anaphylaxis in 71 analysed cases.

NICE provides guidance regarding discharge, compliance with which is highlighted in table 2. 66\% of children had a known allergy; $72 \%$ of which were admitted with a reaction to their known allergen. $55 \%$ of children known to carry an adrenaline autoinjector used it correctly on this occasion.

The results of the survey are shown in table 3. Anaphylaxis recognition was poorer amongst Emergency Medicine trainees compared with General Practice and Paediatric trainees. Regarding management, lower scores were seen in the more senior paediatric trainees and general practise trainees.

Conclusions Our results identify aspects of good practise but also areas for improvement, especially regarding discharge information. The proportion of children being admitted with anaphylaxis to a

\section{Abstract G87 Table 1}

\begin{tabular}{|l|c|}
\hline \multicolumn{1}{|c|}{ Initial Management } & Percentage of children who received intervention (\%) \\
\hline Adrenaline IM & 66 \\
(pre-hospital + in hospital) & $(33 ; 33)$ \\
\hline Antihistamines & 89 \\
\hline Steroids & 87 \\
\hline Pxygen & 37 \\
\hline Fluids & 17 \\
\hline Nebulised salbutamol & 76 \\
\hline
\end{tabular}

\section{Abstract G87 Table 2}

\begin{tabular}{|l|c|}
\hline \multicolumn{1}{|c|}{ On discharge } & $\begin{array}{c}\text { Percentage of children } \\
(\%)\end{array}$ \\
\hline Allergy clinic follow up planned & 92 \\
\hline Issued with adrenaline autoinjector & 69 \\
\hline Documented training in autoinjec tor use if given & 73 \\
\hline Patients rece iving discharge information about anaphylaxis & 73 \\
\hline $\begin{array}{l}\text { Patients rece iving discharge information fulfilling the criteria stated } \\
\text { by NICE }\end{array}$ & 0 \\
\hline
\end{tabular}

Abstract G87 Table 3

\begin{tabular}{|l|c|c|}
\hline & Trainees & $\begin{array}{c}\text { Final Year Medical } \\
\text { Students }\end{array}$ \\
\hline Mumber of respondents & 94 & 184 \\
\hline Mean clinical features score (maximum 20) & 11.9 & 11.2 \\
\hline Mean anaphylax is features score (maximum 8) & 7.0 & 6.5 \\
\hline Mean manage ment score (maximum 6) & 5.1 & 4.4 \\
\hline Percentage identifying need for admission under paediatrics & $85 \%$ & $86 \%$ \\
\hline Percentage identifying need for alle rgy clinic follow up & $88 \%$ & n/a \\
\hline $\begin{array}{l}\text { Percentage who felt competent to teach autoinjector } \\
\text { technique }\end{array}$ & $63 \%$ & nia \\
\hline $\begin{array}{l}\text { Percentage who felt confident at recognising araphylaxis } \\
\text { independently }\end{array}$ & n'a & $56 \%$ \\
\hline
\end{tabular}

